\title{
ESTIMATION OF DIFFERENT NUMERICAL PULSE TUBE THERMOACOUSTIC REFRIGERATOR MODELS
}

\author{
Nekrasova S.O. ${ }^{1 *}$, Sarmin D.V. ${ }^{1}$, Shimanov A.A. ${ }^{1}$,Uglanov D.A. ${ }^{1}$ \\ ${ }^{1}$ Department of heating engineering and heat engines, Samara State Aerospace University, Moskovskoe shosse 34, 443086, \\ Samara, Russia, *yhoji@yandex.ru
}

Keywords: thermoacoustic refrigeration, oscillatory flow, computational modeling, pulse tube, porous media.

\section{Introduction}

The design of the pulse tube refrigerators has continually evolved since the invention of the main PTR [1] with the aim of improving their performance. Last modification of the design was the refrigerator with the inertance tube (IPTR), which established the necessary phasing between speed and pressure, Cha et al. [2] presented the results of numerical simulations in FLUENT, Ashwin et al. [3] used a thermal non-equilibrium model for the simulation of processes in cryocooler. Thus, the aim of the research was the estimation of applicability of parallel methods: thermodynamic and finite-difference simulation in an integrated approach for the design engineering methodology of the thermoacoustic pulse tube refrigerator.

For the first step of OPTR design engineering methodology to get the optimum dimensions in terms of a minimum level of cooling the thermodynamic model of calculating parameters of the cryocooler was used [10]. The geometry, dimensions of OPTR and cases of studies are the same of [4] to be able to compare the calculated results with the experimental data presented in this paper (Fig. 1). The theoretical model of an idealized operating cycle describes 1) the filling process of cryocooler, 2) pressing of the fluid through the OPTR axis, 3) isentropic expansion in the pulse tube with heat rejection in the hot heat exchanger and 4) irreversible adiabatic compression of the gas in the compliance volume, 5) irreversible adiabatic and 6) isentropic expansion of the gas during the return stroke of the piston. The calculation was made with the assumption of an ideal heat transfer in the both heat exchangers, regenerator; the processes in the pulse tube and the compliance volume were assumed adiabatic, hydraulic resistance along the length of the OPTR was not considered, operating cycle was described as step-like process with instantaneous changes of flow parameters in cryocooler. The energy conservation equation for an open thermodynamic system, the equation of state and equation considering pressure changing as a function of temperature of the fluid was solved for each element of the OPTR geometry. Three different cases of mass fluid distribution from the pulse tube into the compliance volume during the OPTR operating cycle were considered [5]. The calculation was performed for the three cryocooler operating modes (Table 1) similar [4], the pressure in the compliance volume for the each operating mode were obtained by the authors using OPTR numerical simulation in ESI ACE +. Computational results show deviations from the experimental values of $5-8 \%$ (Table 2).

An integrated approach of design methodology was to execute an additional modeling of OPTR in two software products ESI CFD ACE + and Fluent. 
Table 1. List of operating modes at $65 \mathrm{~Hz}$ simulated

\begin{tabular}{|c|c|c|c|c|c|}
\hline № & $\begin{array}{c}\text { Mean } \\
\text { pressure } P_{0}(\mathrm{MPa})\end{array}$ & $\begin{array}{c}\text { Mean pressure in } \\
\text { compliance volume } P_{P 1} \\
(\mathrm{MPa})\end{array}$ & $\begin{array}{c}\text { Pistone } \\
\text { displacement } \\
\text { Ao, } \mathrm{m}\end{array}$ & $\begin{array}{c}\text { Texp, } \\
K \\
{[9]}\end{array}$ & $\begin{array}{c}\text { Gas } \\
\text { temperature in } \\
\text { cold heat } \\
\text { exchanger } \bar{T}, K\end{array}$ \\
\hline 1 & 1.4 & 1.375 & 0.00210 & 142 & 154.4 \\
\hline 2 & 1.74 & 1.715 & 0.00195 & 129 & 134.5 \\
\hline 3 & 2.2 & 2.167 & 0.00175 & 126.5 & 123.2 \\
\hline
\end{tabular}

The simulation of 10 seconds duration of each OPTR operating mode was produced. Temperatures on the cold heat exchanger were recorded every $0.1 \mathrm{~s}$. For modeling the processes in OPTR using the program Ansys Fluent was built similar 2-D model in size [4] and it was set the appropriate settings of the boundary conditions. Depending on the frequency step is changed from $0.11 \cdot 10^{-3} . .0 .15 \cdot 10^{-3} \mathrm{~s}$. The results of the calculation are presented in table 2 .

Table 2: The temperature of the gas in the cold heat exchanger 10 seconds of work

\begin{tabular}{|c|c|c|c|c|c|c|c|c|c|}
\hline № mode/frequency & $1 / 55$ & $1 / 55$ & $1 / 55$ & $2 / 65$ & $2 / 65$ & $2 / 65$ & $3 / 75$ & $3 / 75$ & $3 / 75$ \\
\hline CFD-ACE & 155 & 155 & 152 & 152 & 151 & 150 & 150 & 150 & 142 \\
\hline Fluent & 167 & 148 & 137 & 174 & 144 & 136 & 164 & 153 & 128 \\
\hline
\end{tabular}

Thermodynamic model demonstrated the discrepancy 5-8\% between the results of the cold heat exchanger temperature from the experimental data [4] that is quite acceptable for a preliminary assessment of the OPTR cooling level and the amount of heat that can get the load heat exchanger. Comparative analysis of simulation results in OPTR based on the three methods showed similar temperatures and geometrical relations coolers. This fact allows us to conclude that the design phase of the newly created OPTR it is enough to use one of the methods, or their combination. This enables better-informed and more rational use of highlevel techniques for revised calculations.

\section{References}

[1] Gifford, W., Longsworth, R. “Pulse-tube refrigeration. Trans ASME”, J Eng Ind (series B) 1964; 86: $264-268$.

[2] Cha, J.S., Ghiaasiaan, S.M., Desai, P.V., Harvey, J.P., Kirkconnell C.S., “Multi-dimensional flow effects in pulse tube refrigerators", Cryogenics, 46, (2006), 658-665.

[3] Ashwin, T.R., Narasimham, G.S.V.L.., Subhash Jacob. “CFD analysis of high frequency miniature pulse tube refrigerators for space applications with thermal non-equilibrium model", Applied Thermal Engineering , 30 (2010), 152-166.

[4] Dion Savio Antao, Bakhtier Farouk. "Experimental and numerical investigations of an orifice type cryogenic pulse tube refrigerator" Applied Thermal Engineering, 50 ,(2013), 112-123.

[5] Mikulin,E., Tarasov, A., Shkrebyonock, M. "Low-temperature expansion pulse tubes". Adv. Cryogen. Eng., $29,629-637$. 